\title{
System-of-Systems Navigator: An Approach for Managing System-of-Systems Interoperability
}

\author{
Lisa Brownsword \\ David Fisher \\ Ed Morris \\ James Smith \\ Patrick Kirwan
}

April 2006

Integration of Software-Intensive Systems Initiative

Technical Note

CMU/SEI-2006-TN-019

Unlimited distribution subject to the copyright. 
This work is sponsored by the U.S. Department of Defense.

The Software Engineering Institute is a federally funded research and development center sponsored by the U.S. Department of Defense.

Copyright 2006 Carnegie Mellon University.

NO WARRANTY

THIS CARNEGIE MELLON UNIVERSITY AND SOFTWARE ENGINEERING INSTITUTE MATERIAL IS FURNISHED ON AN "AS-IS" BASIS. CARNEGIE MELLON UNIVERSITY MAKES NO WARRANTIES OF ANY KIND, EITHER EXPRESSED OR IMPLIED, AS TO ANY MATTER INCLUDING, BUT NOT LIMITED TO, WARRANTY OF FITNESS FOR PURPOSE OR MERCHANTABILITY, EXCLUSIVITY, OR RESULTS OBTAINED FROM USE OF THE MATERIAL. CARNEGIE MELLON UNIVERSITY DOES NOT MAKE ANY WARRANTY OF ANY KIND WITH RESPECT TO FREEDOM FROM PATENT, TRADEMARK, OR COPYRIGHT INFRINGEMENT.

Use of any trademarks in this report is not intended in any way to infringe on the rights of the trademark holder.

Internal use. Permission to reproduce this document and to prepare derivative works from this document for internal use is granted, provided the copyright and "No Warranty" statements are included with all reproductions and derivative works.

External use. Requests for permission to reproduce this document or prepare derivative works of this document for external and commercial use should be addressed to the SEI Licensing Agent.

This work was created in the performance of Federal Government Contract Number FA8721-05-C-0003 with Carnegie Mellon University for the operation of the Software Engineering Institute, a federally funded research and development center. The Government of the United States has a royalty-free government-purpose license to use, duplicate, or disclose the work, in whole or in part and in any manner, and to have or permit others to do so, for government purposes pursuant to the copyright license under the clause at 252.227-7013.

For information about purchasing paper copies of SEI reports, please visit the publications portion of our Web site (http://www.sei.cmu.edu/publications/pubweb.html). 


\section{Contents}

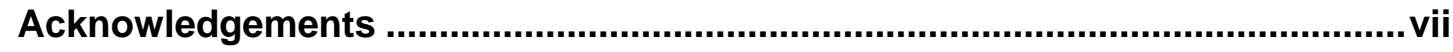

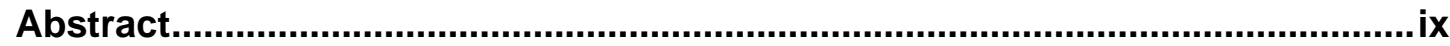

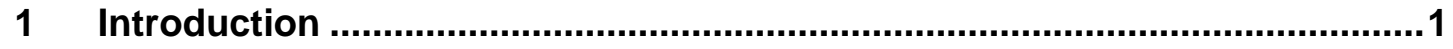

1.1 Overview of This Technical Note ......................................................... 2

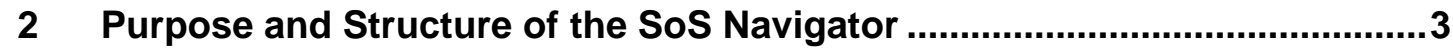

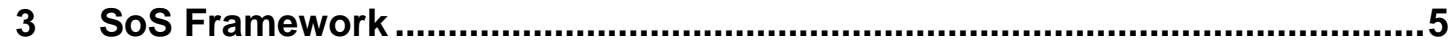

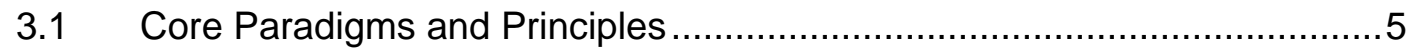

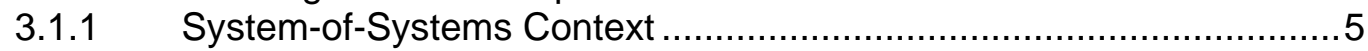

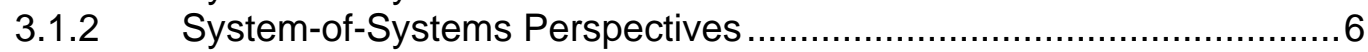

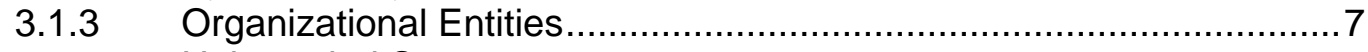

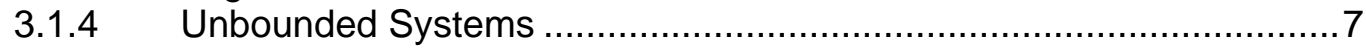

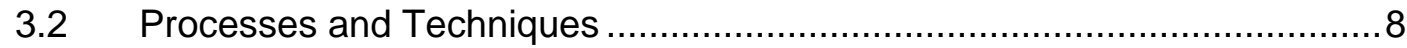

3.2.1 Interoperability Maps ............................................................. 9

3.2.2 Processes for Managing Interoperability Relationships...................13

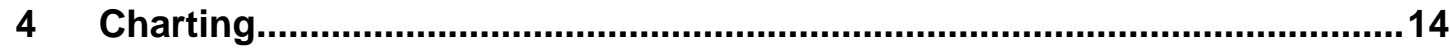

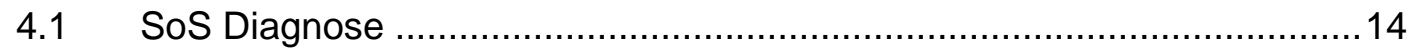

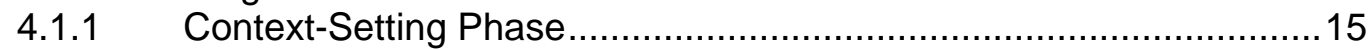

4.1.2 Data-Gathering Phase ...................................................... 16

4.1.3 Using Interoperability Maps ............................................... 16

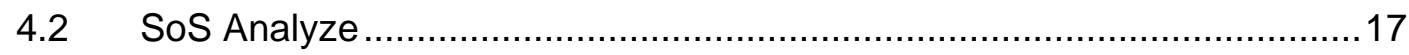

4.2.1 Data Analysis and Findings Phase ........................................ 17

4.2.2 Recommendations and Results Phase ...................................... 18

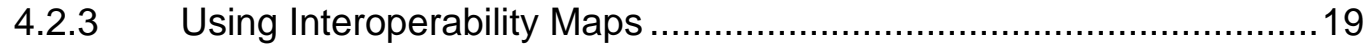

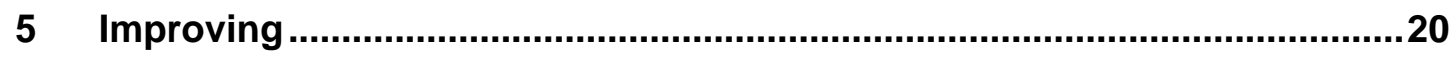

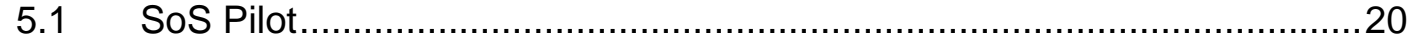

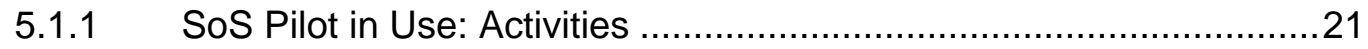

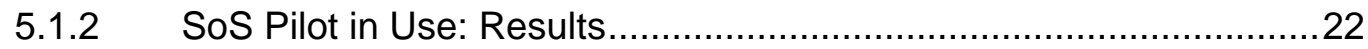

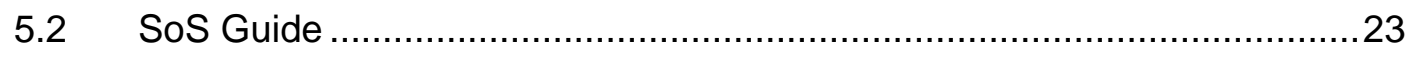

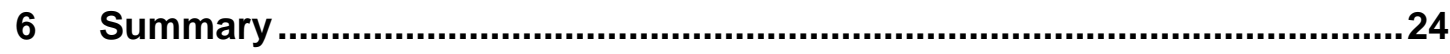

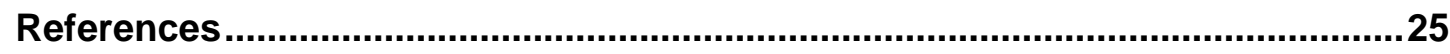




\section{List of Figures}

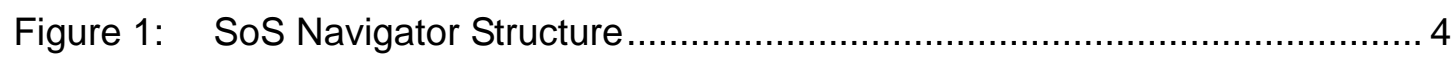

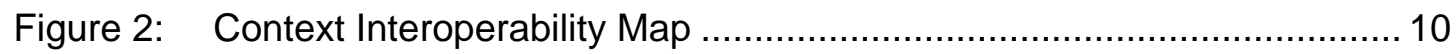

Figure 3: Node-centric Interoperability Map ........................................... 11

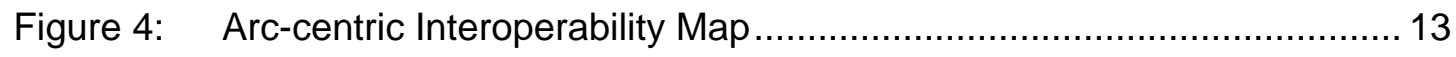




\section{List of Tables}

Table 1: Example Charting Team Recommendations ..................................... 18 


\section{Acknowledgements}

This work has been supported and encouraged by the Office of the Secretary of the Air Force/ Acquisition Integration. This support has enabled the Carnegie Mellon ${ }^{\circledR}$ Software

Engineering Institute Integration of Software-Intensive Systems team to generalize the System-of-Systems Navigator process for application to a broader constituency.

(B) Carnegie Mellon is registered in the U.S. Patent and Trademark Office by Carnegie Mellon University. 


\section{Abstract}

We have crossed a threshold where most of our large software systems can no longer be constructed as monoliths specified by a single, focused, and unified team; implemented as a unit; and tested to be within known performance limits. They are now constructed as groups of interoperating systems (as systems of systems) developed by different but sometimes related teams and made to interoperate through various forms of interfaces. Unfortunately, while we can easily conceive these large systems of systems, we have trouble building them. Software engineering practices have not kept pace, and the problem will only get worse as the community begins to build Internet-scale systems of systems like the Global Information Grid.

This technical note introduces the System-of-Systems Navigator (SoS Navigator), the collection and codification of essential practices for building large-scale systems of systems. These practices have been identified through the work of the Integration of SoftwareIntensive Systems Initiative at the Carnegie Mellon Software Engineering Institute. SoS Navigator provides tools and techniques to characterize organizational, technical, and operational enablers and barriers to success in a system of systems; identify improvement strategies; and pilot and institutionalize these strategies. 


\section{Introduction}

We have crossed a threshold where most of our large software systems can no longer be constructed as monoliths specified by a single, focused, and unified team; implemented as a unit; and tested to be within known performance limits. They are now constructed as groups of interoperating systems (systems of systems) developed by different but sometimes related teams and made to interoperate through various forms of interfaces.

However, we have reached limits in our ability to build even moderately large and interrelated systems of systems using traditional engineering practices. The size and complexity of those systems, the number of people they involve, and the difficulty in specifying what the interrelated systems are supposed to do and how they are to do it lead to almost ubiquitous cost overruns - and frequently complete failures. Furthermore, the systems of systems that are built tend to be inflexible and difficult to maintain. Also, they are subject to change due to complex business rules that are tightly interconnected with the rest of the application. For example, it is noted in System of Systems Interoperability (SOSI): Final Report that even when systems can be interconnected, the connections frequently break down as new versions of individual systems are constructed [Morris 04].

Large-scale systems of systems such as the U.S. Army's Future Combat Systems (FCS) are proving to be very expensive and difficult to build [Francis 04]. Also, a number of planned Internet-scale capabilities represent a step beyond even today's most complex systems of systems. For example, the U.S. Department of Defense (DoD) is beginning to build the Global Information Grid (GIG), which is the globally interconnected set of information capabilities, processes, and personnel that support the vision of network-centric warfare (NCW) [GPO 00]. The Department of Homeland Security (DHS) is investigating ways to provide systems that connect military, civil security, medical, and other agencies to provide coordinated response in the event of a terrorist attack. The medical community wishes to connect doctors, hospitals, insurance companies, pharmacies, and laboratories into networks that provide the means to reduce the cost and improve the quality of medical care [CSI 05, HHS 05].

The problems manifest with moderately large systems today will only get worse as we move toward large- and Internet-scale systems of systems. Research is underway to develop new approaches for building and acquiring systems of systems. For example, the Taiga research project at Brown University focuses on Internet-scale computing and is finding that its complexity represents a "new reality [that] will require us to change the way we think about 
programs and programming." In 2003, Carnegie Mellon University offered a graduate course titled Internet-Scale Sensor Systems: Design and Policy. ${ }^{2}$ The Workshop on InternetScale Software Technologies (TWIST 99) aims to gather participants from industry and academia that are researching or developing software technologies that scale to the Internet. ${ }^{3}$ The Carnegie Mellon ${ }^{\circledR}$ Software Engineering Institute (SEI) is currently completing a study to characterize ultra-large systems (ULS) and their technical and research challenges.

It is important now to initiate practices that help us build the large systems of systems of the near and intermediate future and anticipate those necessary for the Internet-scale systems and ULS of the future. Those practices need to allow each component to be independently specified, designed, and built - as long as the constituents embrace the protocols, standards, and conventions deemed necessary for interoperation. What makes these practices so critical is that these near-term systems of systems will become major components of Internet-scale systems in the future, since it will be economically infeasible to start over and build all new components.

This technical note introduces the System-of-Systems Navigator (SoS Navigator), an integrated set of practices that address the challenges related to achieving effective interoperability in a systems-of-systems context. SoS Navigator is a result of the work of the Integration of Software-Intensive Systems (ISIS) Initiative at the SEI. ISIS is currently working with the largest systems of systems of today and the intermediate-term future to identify, mature, and transition software engineering methods and techniques that enable organizations to integrate components, systems, and systems of systems. ${ }^{4}$ Team members of ISIS also provide guidance on the selection and use of technologies and methods to develop, implement, and evolve interoperable systems.

\subsection{Overview of This Technical Note}

Section 2 provides an overview of SoS Navigator and its structure. Section 3 describes the foundational element, the SoS Framework. Section 4 summarizes the Charting elements, called SoS Diagnose and SoS Analyze. Section 5 describes the Improving elements, named SoS Pilot and SoS Guide. Section 6 provides closing remarks.

For more information on this project, go to http://www.cs.brown.edu/research/projects/taiga.html.

For more information, visit http://www.cs.cmu.edu/ srini/15-829A/.

For more details, go to http://www.isr.uci.edu/events/twist/twist99/.

(B) Carnegie Mellon is registered in the U.S. Patent and Trademark Office by Carnegie Mellon University.

4 ISIS has been involved in systems-of-systems efforts such as FCS, federal and commercial medical systems, satellite constellations, and the GIG. 


\section{Purpose and Structure of the SoS Navigator}

SoS Navigator is an integrated set of practices that address the challenges related to achieving effective interoperability in a systems-of-systems context. SoS Navigator is strongly influenced by the belief that state-of-the-art systems of systems like FCS and future Internetscale systems of systems like the GIG are approaching or will reach a state that has the following characteristics:

- The constituents ${ }^{5}$ of such large-scale systems will be so highly dynamic that the systems of systems are essentially unbounded - constantly growing and shrinking — with no authority having complete knowledge of all of the parts. This circumstance is in contrast to a closed system with rigid, impermeable boundaries and normally well-defined control authorities.

- The stakeholders of the constituent systems will be highly diverse and will have motivations that compete or conflict with those that provided the impetus for the effort to build the system of systems.

- There will be no clear development, acquisition, and operation cycles for the system of systems as a whole. These systems of systems will not be "built" in the sense that a master architect envisions the parts and their relationships; rather they will evolve into existence and change through their life cycles as new constituents are built, existing systems connect to become constituents, and constituents leave.

SoS Navigator helps organizations chart a technical, organizational, and operational path through the system-of-systems environment and prepare for the even more demanding environments of the future. SoS Navigator is composed of these major elements:

- SoS Framework-codifies core paradigms, principles, processes, and techniques associated with effective systems of systems

- SoS Diagnose-identifies and characterizes the enablers and barriers for a particular system of systems

- SoS Analyze - applies the SoS Framework to the information uncovered during the SoS Diagnose element to identify improvement strategies for the system-of-systems effort

- SoS Pilot-demonstrates and prototypes selected systems-of-systems practices in a particular system-of-systems context

- SoS Guide-provides mechanisms for institutionalizing improvements of systems-ofsystems practices across the stakeholders of a system of systems

5 For our purposes, the term constituents refers to autonomous components of a system of systems. Constituents can be automated or mechanized and can also mean individuals or organizations. When referring to constituents represented in graphs, we will typically call them nodes. When we intend a reference to individuals or organizations only, we will use stakeholders. 
As shown in Figure 1, the SoS Framework element provides the overall foundation for the SoS Navigator structure and informs each of the other elements. Collectively, the SoS Diagnose and SoS Analyze elements assist organizations to chart where they are and determine where they should go. Similarly, SoS Pilot and SoS Guide collectively assist organizations to improve their system-of-systems practices based on the results of that charting.

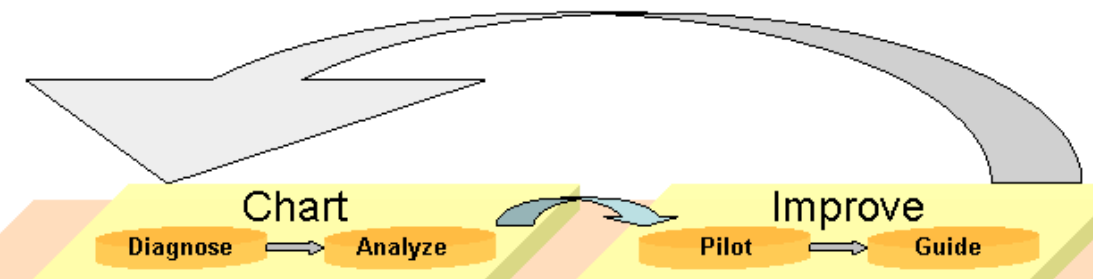

Framework

\section{Figure 1: SoS Navigator Structure}

The elements SoS Diagnose, SoS Analyze, SoS Pilot, and SoS Guide are applied iteratively as necessary to enhance the capabilities of system-of-systems constituent organizations. These elements can be used at any stage of a system of systems. They can also be used periodically as needed throughout the life of a system of systems.

The SoS Navigator elements are explained further in the following three sections: (1) SoS Framework in Section 3, (2) Charting (for SoS Diagnose and SoS Analyze) in Section 4, and (3) Improving (for SoS Pilot and SoS Guide) in Section 5. 


\section{SoS Framework}

The SoS Framework element is a diverse set of core paradigms and principles along with processes and techniques that the ISIS Initiative has developed in our work with organizations attempting to build, field, and evolve systems of systems. ${ }^{6}$ We expect to continue refining and expanding this body of knowledge through our collaborations with system-of-systems practitioners and other research organizations.

\subsection{Core Paradigms and Principles}

Within the SoS Framework element, information associated with core paradigms and principles can be organized into several interrelated categories. These categories of information include

- system-of-systems context

- $\quad$ system-of-systems perspectives

- $\quad$ system-of-systems organizations

- unbounded systems

The following sections identify some of the key points within these categories.

\subsubsection{System-of-Systems Context}

Understanding the context in which large-scale systems of systems are built and operated is essential to understanding the types of processes and techniques that will be successful. The following fundamental statements about systems of systems reveal this context.

- A system of systems is more than "just" hardware and software. Systems of systems are composed of various types of constituents, including computing components (e.g., hardware/software components), organizations that build and operate those components, and the individual people within those organizations. All of the influences arising from the interactions among those constituents must be considered-whether from common, competing, and conflicting motivation and intent or differing needs and expectations.

- A system of systems has a purpose, even when individual constituents do not share the overall intent of the people or organizations that conceived it. In fact, it is common for some individual constituents not to share in the overall intent, yet still participate in a system of systems. Perhaps the most common example of this aspect is the commercial

${ }^{6}$ We use the term framework with considerable caution because it has several different meanings. Our definition is intended only in reference to SoS Navigator. 
off-the-shelf (COTS) component that provides a capability to many systems of systems but does not share in the intent of any those systems. As Internet-scale systems of systems become possible, they will likely incorporate many constituents that do not share the overall intent.

- A system of systems is built to operate within a specific cultural, business, and legal environment. This circumstance constrains how and why the system of systems is built and determines the types of constituents that can be involved. It often also imposes restrictions (e.g., security). However, large-scale systems of systems must frequently incorporate constituents that do not share all elements of the environment.

- A system of systems is subject to constantly changing needs, technologies, and environment. In a system of systems, there is a need to explicitly address uncertainty and unanticipated changes, since the requirements of users, the environment in which the system of systems operates, and the technologies that populate the system of systems are bound to change over time.

- Adaptability and scalability are key requirements. To a much greater extent than for monolithic systems, there is a need for systems of systems to be scalable in a costeffective fashion and adapt to the changing circumstances. Continual evolution is a characteristic of system of systems [Carney 05]. The nature and rate of evolution of the interoperability relationship are critical.

\subsubsection{System-of-Systems Perspectives}

The multiple organizations involved in systems of systems will have different perspectives on technology, organizational relationships, commitments, and other factors. One organization may be unaware of the perspectives of some other organizations - or even of their existence.

To achieve interoperation in a system-of-systems context, a diverse set of stakeholders across many organizations must coordinate efforts and recognize multiple perspectives - in management, assembly, and operations — as detailed below:

- management

This perspective on interoperability is concerned with issues such as schedules, risk management, supplier coordination through contracts, motivation, incentives, and teamwork.

- assembly

This perspective is concerned with system and software development, maintenance, and evolution activities, such as forming the architecture, testing and integrating systems effectively, and transitioning systems to the user community.

- operations

This perspective is concerned with activities performed by the end user in the actual operation of the system.

The complex relationships of the critical stakeholders across those perspectives need to be managed throughout the lifetime of the system of systems. 


\subsubsection{Organizational Entities}

In addition to differing perspectives, systems of systems involve several distinct organizational entities.

\section{- global system-of-systems entity}

In any system of systems, there is an entity that represents its global capability. In some cases, this entity is an actual program. For example, FCS is a program of record trying to construct a system of systems. Also, in the Joint Battle Management Command and Control System, the entity exists (i.e., U.S. Joint Forces Command [USJFCOM]) but does not have managerial control over all the constituent systems. A global system-ofsystems entity exists even in cases where the system of systems is dynamically composed of constituents that are unaware of the existence of the system of systems. The global entity is responsible for the composition of the constituents.

- autonomous (or semiautonomous) constituents

Constituents in a system of systems often operate with an unexpected degree of independence. This independence is sometimes the result of the distinct acquisition and management authorities for the constituents. The complexity of many systems of systems and the competing demands of independent and system-of-systems operation lead to surprisingly independent constituents, even when they are under the managerial control of a single entity. Each constituent often evolves independently from other constituents, but it contributes to the overall evolution of the system of systems.

- communities of interest (COIs)

Stakeholders responsible for constituents in large-scale (and in the future, for Internetscale) systems of systems often find advantages in forming alliances of common interest. Those alliances tend be relatively long-lived, such as an alliance of command and control interests working together to establish common interfaces.

- neighborhoods

Related to COIs, but more dynamic, are neighborhoods, which reflect that constituents must interact for a given purpose. At any given time, an individual constituent will be a member of many neighborhoods. For example, one neighborhood may include other constituents with related schedule dependencies. Another neighborhood may be based on a shared technical decision. A third sort of neighborhood may be based on execution pathways. In dynamically composed systems of systems, such neighborhoods may exist only for a specific execution sequence.

Sometimes these entities are aligned for a common purpose. More often, their purposes are misaligned to some degree.

\subsubsection{Unbounded Systems}

Some of today's large systems of systems (like FCS) and all Internet-scale systems of systems of the future are examples of unbounded systems, in which an unknown number of 
participants might interact at any given instance. Unboundedness leads to consequences such as

\section{- emergence}

Unbounded systems display behaviors that differ from, and are not easily foreseen as arising from, the collective properties of the constituents that make up the system of systems. These global behaviors emerge from the cumulative actions and interactions of the constituents propagated throughout the system of systems and can have a positive or negative effect. In the best case, emergent properties will provide unanticipated benefits to the users of the systems of systems. For example, Internet Protocol routing is surprisingly resilient, due to the emergence of unanticipated pathways for communication. In the worst cases, emergent properties will destroy system-of-systems capabilities, as can occur when circuits reverberate with information repeatedly passed around the Internet.

- limited visibility

No individual constituent perceives the entire system. Instead, all constituents must deal with incomplete information about the other participants and the current operational situation.

- inadequacy of traditional systems engineering approaches

Many traditional approaches will not work, in fact. Tight coupling among systems, central process and data control, hierarchical architectures, and top-down enforcement of all-encompassing standards - all are unlikely to lead to capable and flexible systems of systems. Those approaches were developed for a context in which the development and evolution of constituents were controlled by a shared management.

Algorithms for unbounded systems are being identified. New methods include

- ways to take advantage of emergent properties by encouraging cooperation without tight or inflexible coordination

- dynamic adaptation to changing circumstances

- means to identify and capitalize on opportunistic interactions

- anticipatory assistance to neighbors

- built-in resilience and redundancy in architectures

\subsection{Processes and Techniques}

As noted in the preceding sections, many traditional engineering and management processes, methods, and techniques do not scale and are often inadequate for today's system of systems - let alone for the Internet-scale systems of tomorrow. Driven by a model of "thinking globally, yet acting locally," we need new paradigms that encompass practices in the following situations:

- No one stakeholder group or individual can have complete system-of-systems insight.

- Central control has limited effectiveness; distributed control is essential. 
- System-of-systems capabilities and properties emerge from cumulative, indirect effects of local actions and neighbor interactions.

- Broader sets of stakeholders, including users, must be directly involved throughout the life of a system of systems.

- Local decisions and reward systems must be tempered by understanding of system-ofsystems purpose and goals.

A central aspect to engineering and managing in a system-of-systems environment is an understanding of the relationships among the various constituents. The SoS Framework element includes a set of interoperability maps - graphs to capture information associated with these relationships. Each of the other SoS Navigator elements (i.e., Diagnose, Analyze, Pilot, and Guide) can use this information. The SoS Framework element also includes a set of processes to create, use, and refine this relationship information.

The following sections describe interoperability maps and their associated processes.

\subsubsection{Interoperability Maps}

Interoperability maps characterize the relationships in a system of systems from three perspectives: (1) the global system-of-systems entity, (2) individual constituents (represented as nodes in the graph), and (3) individual agreements (represented as arcs between a pair of nodes).

These maps permit the capture of information about how constituents actually influence one another in a system of systems. That is, they portray the reality of how things work-not how they are supposed to work - and represent actual understandings, intents, and expectations of constituents, as opposed to what is stated in acquisition and design artifacts.

There are three forms of interoperability maps currently in the SoS Framework element.

1. Context Interoperability Map depicts high-level, system-of-systems-wide information about contractual, funding, requirements, hardware, oversight, and build/integrate influence relationships from the global system-of-systems entity perspective.

2. Node-centric Interoperability Map portrays information about contractual, funding, requirements, hardware, oversight, and build/integrate influence relationships from the perspective of individual constituents.

3. Arc-centric Interoperability Map represents information about needs, offers, expectations, intentions, and negotiated agreements between the constituents involved in the influence relationship. 


\section{Context Interoperability Map}

The nodes represented in the Context Interoperability Map are

- $\quad$ systems

- major management entities (e.g., contractors, program offices, or agencies)

- funding organizations (e.g., appropriations committees)

- oversight organizations (e.g., regulatory boards or standards bodies)

- contractual organizations

As the Context Interoperability Map presented in Figure 2 illustrates, arcs connect nodes that have an influence relationship. ${ }^{7}$ These influence relationships can be highly complex, encompassing multiple dimensions of schedule, contracting, and performance. The Context Interoperability Map conveys a general "lay of the land" and may also provide insight into possible areas of the system of systems that would be good candidates for further exploration.

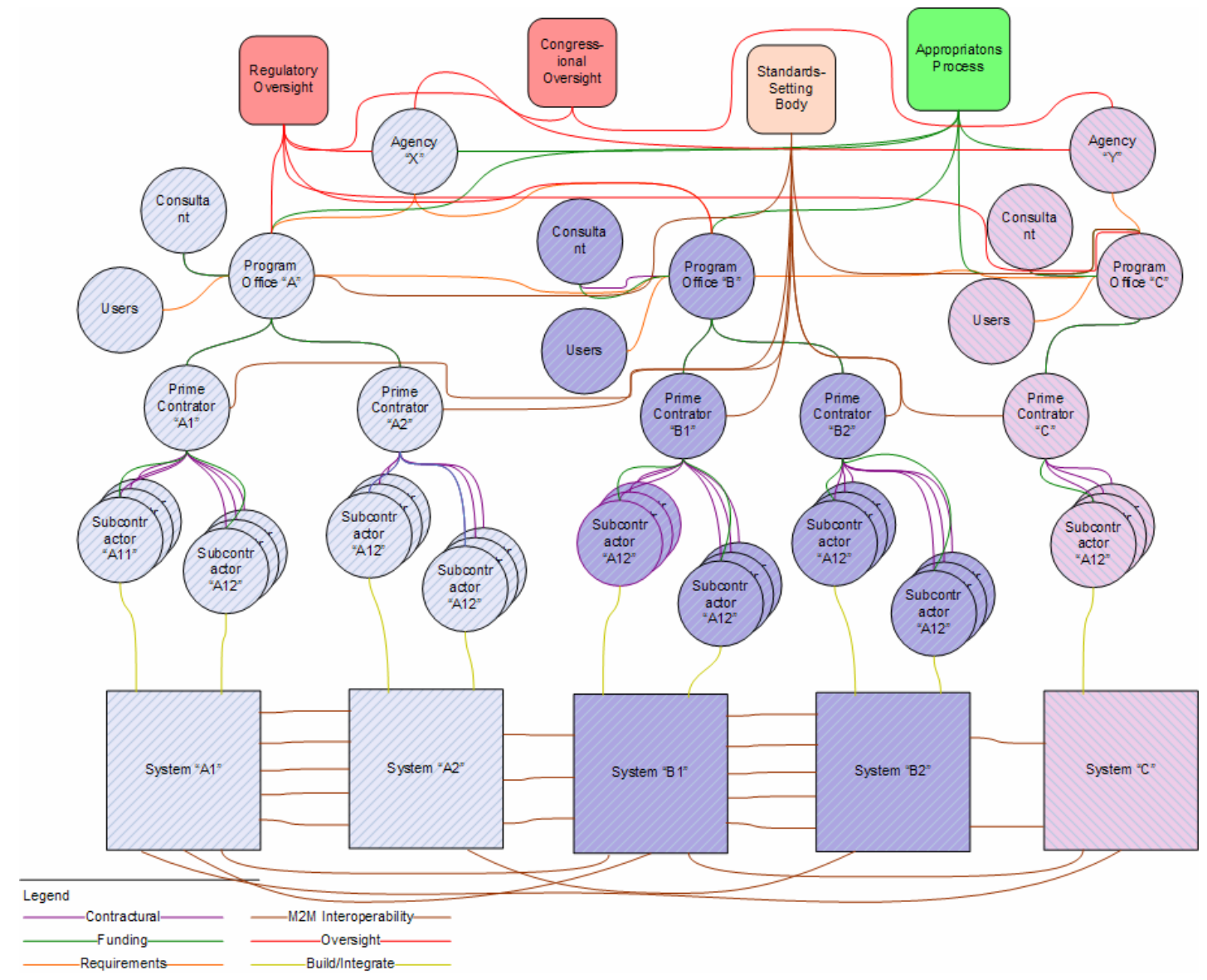

Figure 2: Context Interoperability Map

7 The interoperability maps shown in this section are conceptual models designed to illustrate the kinds of maps produced in the SoS Framework element. They do not reflect an actual system or system effort. 
The Context Interoperability Map allows the SoS Navigator team to capture the broad influences on the system of systems. In effect, this graph represents the viewpoint of the system-of-systems global entity responsible for the overall system of systems. It identifies and documents many individual constituents that participate in the systems-of-systems effort. However, it does not attempt to identify all of the influences that impinge on individual nodes; that is the function of the Node-centric Interoperability Map.

\section{Node-Centric Interoperability Map}

From the standpoint of a constituent, the Node-centric Interoperability Map (shown in Figure 3 ) documents the influences in a system of systems.

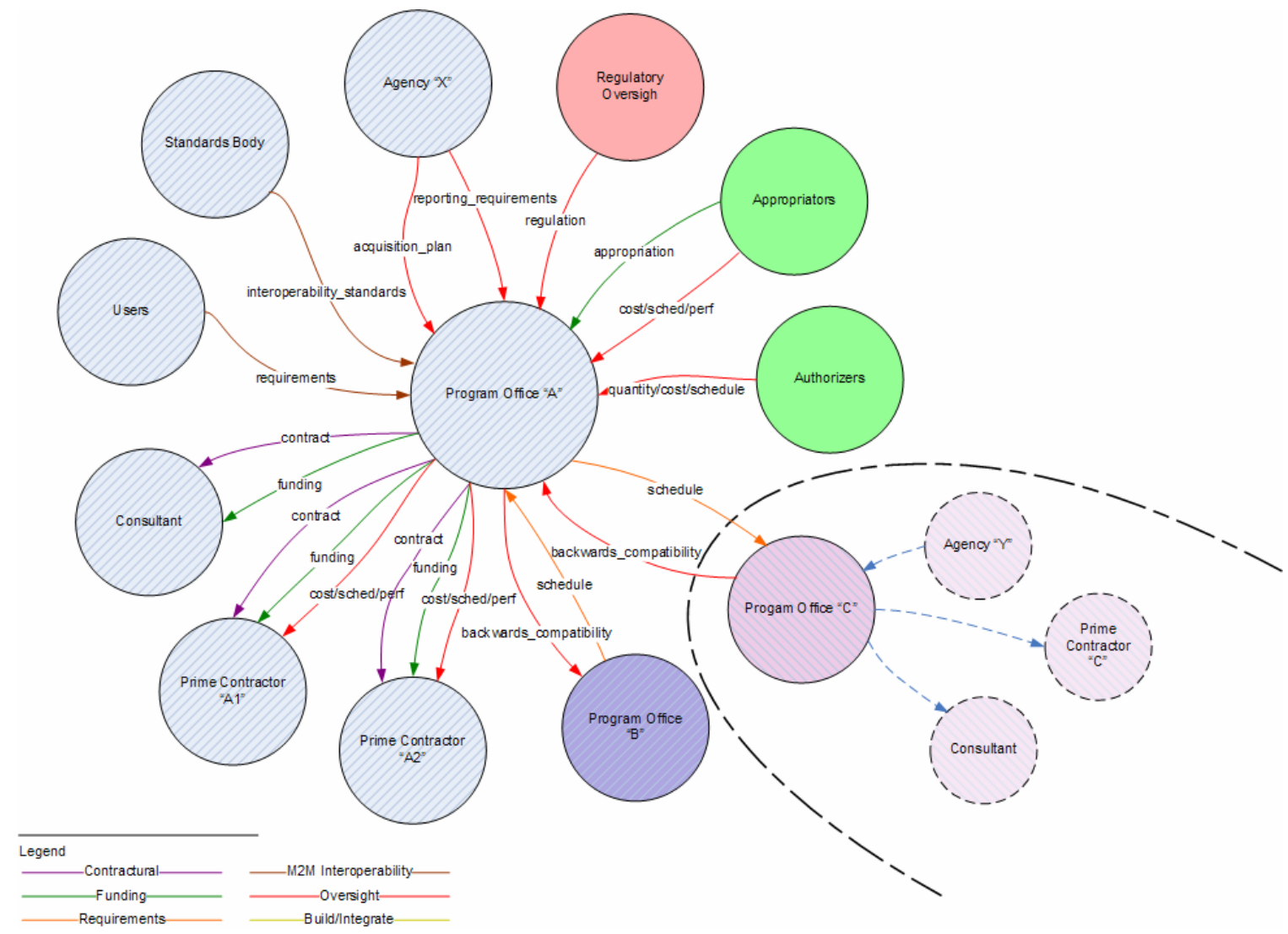

Figure 3: Node-centric Interoperability Map

Node-centric Interoperability Maps are specialized to the perspective of a single program management office, contractor, or other type of constituent. They reveal what is "visible" to the constituent. An important aspect is that a constituent represents the relevant interests of "downstream" constituents to an "upstream" constituent. For example, in Figure 3, Program Office "C" would represent any schedule constraints that it has with any downstream constituents (Agency "Y" and Prime Contractor "C") in its schedule relationship with Program Office "A." This notion of pass-through or transitive influences allows the influence 
relationships affecting a particular constituent to be understood without requiring that constituent to have insight into the entire system of systems.

Figure 3 shows how influence relationships can be fairly complex:

- The direction of an arc represents the primary direction of influence.

- The destination node of each arc (i.e., the "upstream" constituent) has a need that represents the claimed minimal set of critical expectations from the source node of the arc (possibly as function of schedule, value, or quality).

- The arc source node has an offer that represents the broadest set of relevant things that it can feasibly provide to the destination node.

- Each arc has an associated agreement that may be in part implicit, informal, or tacit.

- Agreements derive from negotiation — often informal — of needs and offers.

- Agreements may be vague initially and then refined as detail is needed and understood.

- In combination with the context in which the neighbors operate and the trust they place in their partners, agreements determine the intents and expectations along each arc.

Node-centric Interoperability Maps provide a mechanism to establish consistency between what one constituent believes to be important interrelationships (as reflected in the Context Interoperability Map) and what other constituents believe to be important.

In addition to providing sufficient detail to support the analysis of inconsistencies and conflicts, the Node-centric Interoperability Maps identify relationships to organizations outside of the purview of a global system-of-systems entity. For example, Figure 3 represents relationships between Program Office " $A$ " and several constituents not normally under the purview of most global system-of-systems entities (i.e., appropriators, authorizers, and regulatory oversight bodies). Notice that these constituents can have a significant impact on a system of systems but often are not considered.

\section{Arc-Centric Interoperability Map}

Arc-centric Interoperability Maps express and make explicit the (often implicit) assumptions that go into an influence relationship. They can be used in situations where influence relationships are particularly complex, critical, or easily misunderstood. In an Arc-centric Interoperability Map, as Figure 4 demonstrates, the needs of the requesting constituent are expressed as a set of minimum critical needs (MCNs) - the absolute minimum that is truly necessary to satisfy the requestor's constraints. The response from the offering constituent is expressed as a set of broadest feasible offers (BFOs) - the "most generous" response it can provide that does not violate its constraints. 


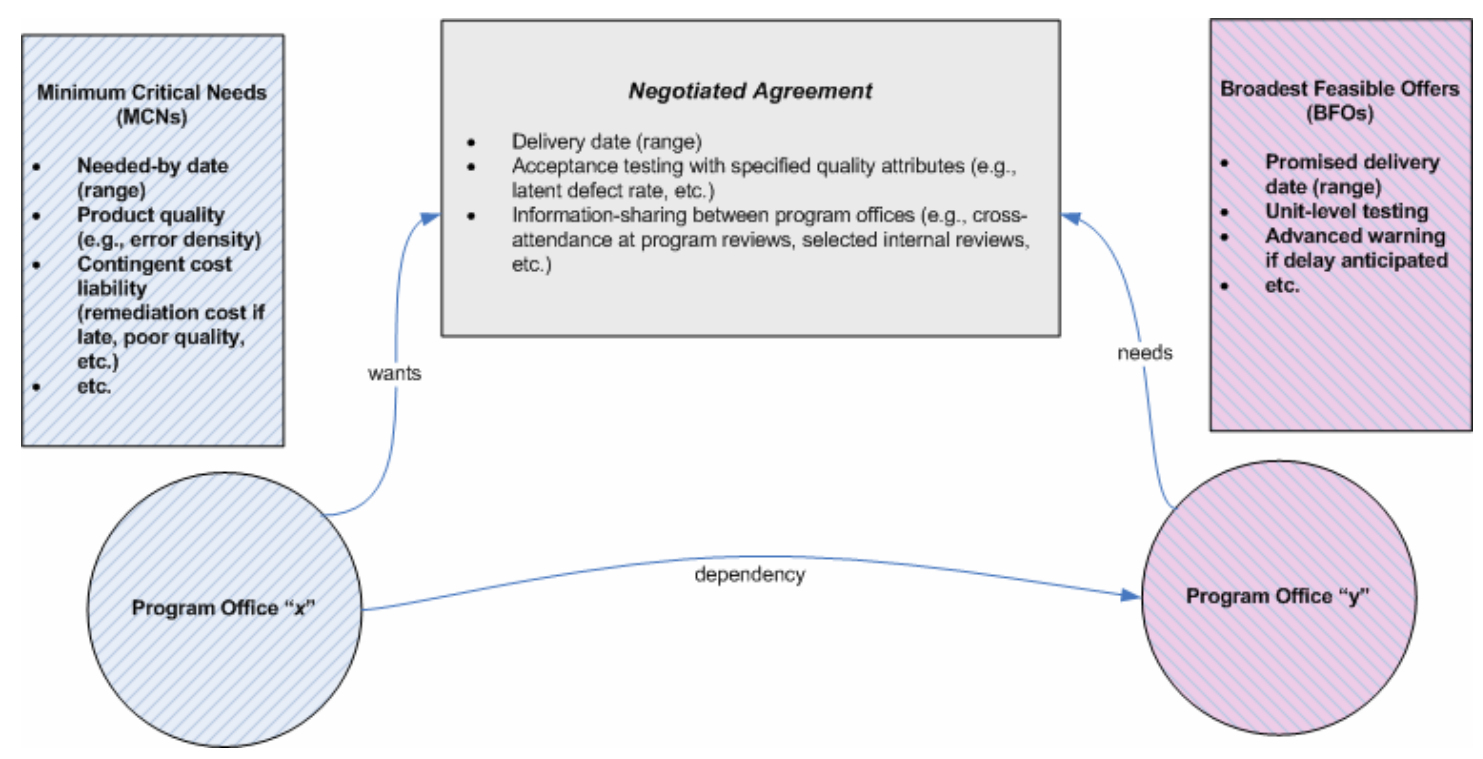

Figure 4: Arc-centric Interoperability Map

Where there is an overlap between the MCNs and BFOs, an agreement is possible; where there is no overlap, no feasible match between the requestor's needs and the offering constituent's capabilities exists. In short, no overlap — even after negotiating (i.e., exploring whether restating needs and offers can possibly result in an overlap) - indicates that no agreement is possible. The focus of Arc-centric Interoperability Maps on MCNs and BFOs is important, because those assumptions represent the end points of a range within which a negotiated agreement is possible. Interestingly, these end points are often not the same as the negotiated agreement, since the agreement often represents a more optimistic view of events.

\subsubsection{Processes for Managing Interoperability Relationships}

The SoS Framework element currently includes these processes to manage the various relationships among constituents for a given system of systems:

- Form and evolve agreements among constituents. This process begins with identifying and characterizing MCNs and BFOs. Through negotiation, common ground is identified.

- Propagate constraints for needs and offers. As parties negotiate and form MCNs and BFOs, they act as a proxy for their "downstream" constituents. This approach provides a mechanism to work more effectively within the nature of unbounded systems.

- Manage intentions and expectations informed by trust. Trust reflects confidence in the information contained in MCNs and BFOs. Divergent expectations and intentions may cause an interoperability problem. 


\section{Charting}

In our experience, many system-of-systems efforts fail because organizations either are unaware of the existence of the paradigms and principles reflected in the SoS Framework element or do not understand their implications. For large- or Internet-scale system-ofsystems efforts to succeed, multiple "world views" must be understood and addressed so that

- the differing and often competing interests of the system-of-systems entities (global system-of-systems entity, autonomous constituents, COIs, and neighborhoods) can be aligned where appropriate and accommodated where necessary

- where competing interests are not well recognized, the fewest number of constraints possible can be imposed on constituents, COIs, and neighborhoods

It is not necessary to ensure that all entities are in lockstep. Rather, the need is to help organizations know when they have to fall in step and when they have freedom to vary. Thus, aligning world views will likely also involve agreeing on what not to constrain. We believe that extracting and understanding the multiple organizational, technical, and operational perspectives-and their interrelationships-helps to effectively

- determine where those relationships are aligned or unaligned across the different systemof-systems entities

- make improvements to the alignment where needed

- establish the minimal agreements that are necessary for participants to work effectively

SoS Diagnose and SoS Analyze, the Charting elements, provide approaches that promote the understanding of the current state of a particular system of systems and determine necessary improvements. The primary objectives of these elements are to provide stakeholders with (1) a profile of the constituents and their primary patterns of relationships, barriers, and enablers to achieving the desired system-of-systems interoperation and (2) recommended actions to enhance the likelihood of success. The Charting Team, composed of two to four members with expertise in the various viewpoints associated with systems of systems, would typically perform the SoS Diagnose and SoS Analyze elements sequentially.

\subsection{SoS Diagnose}

The SoS Diagnose element is a set of techniques designed to assist organizations with problems in program management; system construction and maintenance; or operation of large, complex, heterogeneous, software-intensive systems of systems. The SoS Diagnose element assists organizations in the identification and characterization of key enablers and barriers to achieving and maintaining required levels of interoperability. It also helps 
organizations gain insight into the key relationships forged, information exchanged, and decisions made between constituents.

To gather information about the constituents and the most important relationships, the SoS

Diagnose element calls for a series of structured discussion sessions and workshops with various stakeholders that represent the diverse perspectives of the system of systems.

Quantifiable data and other documented information are used to augment the discussion and workshop sessions. Interoperability maps are an additional technique used to elicit and capture information relevant to management, construction and assembly, and fielding and operations.

The SoS Diagnose element is a collaborative engagement, in which the Charting Team leads various stakeholders associated with the specific system of systems in discussion sessions and workshops. These sessions identify issues, explore causes, expand and validate interoperability information and diagrams, and identify existing effective practices.

The SoS Diagnose element is conducted in two phases, which are summarized in the following sections: 4.1.1 (context setting) and 4.1.2 (data gathering).

\subsubsection{Context-Setting Phase}

In the context-setting phase, participants agree on a scope that will provide sufficient value within the current political, cultural, financial, and scheduling realism of the system of systems to be explored. This phase legitimizes the Charting Team by establishing the contract between it and the sponsoring organization and creates the foundation for the data-gathering phase and, later, the SoS Analyze element. In forming the scope, team members construct realistic expectations of

- communities and organizations that will participate

- $\quad$ process to be used ${ }^{8}$

- result to be achieved (e.g., producing a set of recommendations) at the completion of the companion element, SoS Analyze

During the context-setting phase, the Charting Team seeks to

- establish an overview of the organizational structures

- identify the key players and roles

- discover the common acronyms and culture of the communities and organizations participating in the system of systems

- assimilate general background information on the application domain (Where possible, the general background material comes from existing sources readily available to the

8 The determination of a process to be used must take account of the time-commitment expectations of the participants. 
sponsoring organization, such as technical and nontechnical briefings and other related documentation.)

- form a top-level system-of-systems overview

- determine schedules

- understand funding sources and requirements

The team also collects an initial set of the interoperability challenges or issues facing the organizations. Often, a sponsoring organization already has such a list. Time and disruption for individuals and their organizations is minimized to the extent practical.

\subsubsection{Data-Gathering Phase}

The goal of the data-gathering phase is to execute the data collection process. Materials provided to the Charting Team as part of the SoS Diagnose element include

- a set of discussion topics, templates, and guidelines for organizing the discussion and workshop sessions

- tools for collecting the data gathered

- guidelines for tailoring this phase to the needs of a specific system-of-systems context and the negotiated scope

The discussion and workshop sessions involve staff members who are responsible for or affected by the various elements of the system of systems. These sessions should include as many different perspectives as possible: management, development and maintenance, and operations. A key role for the Charting Team during the sessions is to moderate and focus the discussion on issues related to interoperability and systems of systems. The emphasis during the data-gathering phase is on understanding what is transpiring in a system-of-systems context; it is not a process assessment or a technique to assign blame.

During the discussions and workshop sessions, draft interoperability maps are created, vetted, and revised. The Charting Team typically creates a series of interoperability maps with multiple levels of abstraction and detail. The maps provide a graphical representation that facilitates capturing, understanding, and analyzing relationships among constituents of the system of systems. The following section provides several examples of using interoperability maps as part of the SoS Diagnose element.

\subsubsection{Using Interoperability Maps}

A Context Interoperability Map is initially produced by the Charting Team in conjunction with the global system-of systems entity. During the various discussion and workshop sessions, that Context Interoperability Map is reviewed and revised as necessary. From that map, the Charting Team identifies constituents that require further exploration through Nodecentric Interoperability Maps. 
Draft Node-centric Interoperability Maps and/or Arc-centric Interoperability Maps are created or revised during relevant sessions. The Charting Team facilitates the creating and vetting of the maps, but the information must come from the stakeholders-ideally, system engineers (for the system of systems and individual constituents), managers, operational users, financial personnel, and contracts experts.

For Arc-centric Interoperability Maps, as much information as possible is identified about needs, offers, agreements, context, level of trust, intent, and expectations. The accuracy of this information is essential, but completeness is less so. In other words, the map should contain what is known, but no assumptions should be made about what is unknown. Gathering this information may require interaction with partners in the influence relationships.

\subsection{SoS Analyze}

The information gathered, including the interoperability maps, provides the basic input for the SoS Analyze element. To evaluate that information, the Charting Team makes use of the SoS Framework element and works through the SoS Analyze element to arrive at a set of techniques. Together, those principles and techniques help the team find root causes and patterns. The team's objectives for the SoS Analyze element are to

- characterize enablers and barriers to interoperability and effective system-of-systems operations

- identify potential gaps in the system-of-systems practices

- derive recommendations

- determine next steps to initiate the planning activities of the SoS Pilot element (e.g., what could be done and who should be involved in actual action planning)

The activities associated with the SoS Analyze element are performed by the Charting Team, typically requiring little or no interaction with stakeholders of the system of systems. The SoS Analyze element is composed of two phases:

1. data analysis and findings

2. recommendations and results

\subsubsection{Data Analysis and Findings Phase}

As the name implies, the goal for the data analysis and findings phase is to analyze the information collected from the discussion and workshop sessions, the interoperability maps, and other data sources. When performing the analysis, the Charting Team members use their knowledge of system-of-systems interoperability and consider the insights offered in the SoS Framework element. The team analyzes the interoperability maps for patterns that identify aspects conducive to achieving interoperability or indicative of potential interoperability problems. (See Section 4.2.3 for more information about using interoperability maps.) 
The Charting Team generates a set of findings that address, at a minimum, the interoperability issues identified during the context-setting phase of the SoS Diagnose element. Often additional issues surface during the analysis and are factored into the findings.

\subsubsection{Recommendations and Results Phase}

The culmination of the SoS Analyze element is the development of a set of recommendations for improving the system-of-systems effort. These recommendations reflect the principles of the SoS Framework element and are customized to the needs of a particular system-ofsystems effort and its constituent parts. Some example recommendations from our work with a large government system of systems are shown in Table 1.

Table 1: Example Charting Team Recommendations

\begin{tabular}{|l|l|l|}
\hline \multicolumn{1}{|c|}{ Challenge } & \multicolumn{1}{|c|}{ Analysis } & \multicolumn{1}{c|}{$\begin{array}{c}\text { Charting Team } \\
\text { Recommendation }\end{array}$} \\
\hline $\begin{array}{l}\text { Numerous problems arising } \\
\text { from clashes between } \\
\text { decisions made by } \\
\text { autonomous constituents (in } \\
\text { this case, by individual } \\
\text { programs) }\end{array}$ & $\begin{array}{l}\text { The Context Interoperability } \\
\text { Map indicated that there was a } \\
\text { high degree of coupling between } \\
\text { the various constituents. }\end{array}$ & $\begin{array}{l}\text { Definition of a set of "guiding } \\
\text { principles": each constituent } \\
\text { would abide by those principles } \\
\text { as part of operating in the system } \\
\text { of systems }\end{array}$ \\
$\begin{array}{l}\text { The lack of a clearly articulated, } \\
\text { shared intent for the system of } \\
\text { systems was also contributing to } \\
\text { the problems. }\end{array}$ & $\begin{array}{l}\text { The guiding principles would be } \\
\text { used to influence the cross-system } \\
\text { tradeoffs and help individual } \\
\text { program offices maintain } \\
\text { coherence in their day-to-day } \\
\text { decisions. }\end{array}$ \\
\hline $\begin{array}{l}\text { Limited understanding about } \\
\text { the nature of the } \\
\text { interoperability relationships } \\
\text { between constituents }\end{array}$ & $\begin{array}{l}\text { Many of the relationships were } \\
\text { tacit, implicit, or } \\
\text { unacknowledged and were not } \\
\text { considered adequately as } \\
\text { decisions were made. }\end{array}$ & $\begin{array}{l}\text { Expansion of the draft } \\
\text { interoperability maps with an } \\
\text { initial emphasis on the schedule } \\
\text { relationships and dependencies } \\
\text { among the constituents }\end{array}$ \\
\hline
\end{tabular}

It is vital that the Charting Team communicate its findings and recommendations effectively to the sponsoring organization. To capture and communicate the results, the team should create a briefing or short report. The depth and breadth of the results is based on the scope and expectations negotiated as part of the context-setting phase in the SoS Diagnose element. During the results briefing, the Charting Team will encourage discussion regarding the accuracy of the findings and the feasibility of the recommendations.

Also in this phase, the team seeks to elicit commitment to create an action plan that will address the recommendations. This commitment should include identification of the individuals responsible for leading the action planning team. While the actual planning will 
be performed as part the SoS Pilot element, our experience indicates that it is critical to close out the SoS Analyze element with a plan for initiating the planning process.

\subsubsection{Using Interoperability Maps}

Interoperability maps provide a rich opportunity for analysis. Relationships in the Nodecentric Interoperability Maps, for instance, can suggest possible cascading effects, in which a decision made at a particular node has possible adverse affects on other nodes. The maps can also indicate the span of control from a specific perspective - for example, that of the program manger or of a related agency. Further, "islands" or "continents" of nodes can indicate elements that are entirely outside the span of control from the perspective of a particular organization. Clusters of nodes and arcs can indicate possible bottlenecks-or alternately may provide opportunities for optimization.

Node-centric Interoperability Maps provide an additional level of detail sufficient to

- identify interoperability problems with neighbors and support risk assessment for the node

- allow analysis of the effect of changes at the global level on individual nodes

- permit analysis of the impact of changes at the node level on related nodes

- support decisions at the node level, consistent with global objectives

- identify relationships outside the system-of-systems effort that may constrain decisions or affect the ability to perform as expected

Arc-centric Interoperability Maps provide yet another level of analysis to

- highlight consistencies and inconsistencies between agreements and expectations

- facilitate the identification and analysis of alternate possible agreements

- indicate the possibility of achieving a goal based on the minimum critical needs and broadest feasible offers of the parties involved

- support impact analysis for changes in expectations and intentions 


\section{Improving}

In our experience, a list of recommendations - even quite detailed ones - is insufficient for many organizations to enact measures and effectively derive improvements. Often there are subtleties and interrelationships among recommendations that are easily missed.

Many of the recommendations that come out of the SoS Analyze element demand significant cultural and process changes. These types of recommendations are rarely implemented easily. While some organizations may have existing improvement infrastructures that can be leveraged, there is often little in place for cross-organization collaboration and improvement.

We have found that improvements are realized more effectively when recommendations and their resulting changes to individuals and organizations are planned and managed explicitly. SoS Pilot and SoS Guide, the Improving elements of SoS Navigator, collectively assist stakeholders of a system of systems to

- plan, execute, and manage the implementation of recommendations

- prototype and validate new approaches within the system-of-systems environment

- perform necessary adaptations for the specific environment

- determine viable rollout strategies to the broader set of organizations

- monitor the effectiveness of the new approaches

For a given system of systems, the Improving Team (ideally containing at least one member from the Charting Team, for greater efficiency and continuity) will typically iterate between the activities of the SoS Pilot and SoS Guide elements to enact the recommendations from the SoS Analyze element.

\subsection{SoS Pilot}

The SoS Pilot element is a set of techniques for applying existing improvement approaches where appropriate and adapting them as needed in multiorganizational interactions. It builds on the organization-specific information, findings, and recommendations of the SoS Analyze element and the paradigms, practices, and techniques of the SoS Framework element.

The four primary objectives for the SoS Pilot element are to assist organizational entities to

1. form a new improvement roadmap or revise an existing one for a specific system of systems

2. demonstrate, prototype, and pilot the use of new system-of-systems practices in the specific system-of-systems context 
3. adapt system-of-systems practices as necessary for the local environment without compromising the underlying practice or technique

4. gain commitment to proceed further

In the SoS Pilot element, the Improving Team works with the various system-of-systems entities (i.e., global system-of-systems entity, autonomous constituents, COIs, and neighborhoods) to create (or refine) an implementation roadmap that includes a set of detailed action plans.

The degree of formality of the plans depends on the context (political and cultural environment) of the particular system of systems and the unbounded nature of systems of systems generally. It is impractical for any one entity to have complete visibility and exercise complete control. Because of these constraints, the goal is to find the degree of formality required to be effective, but no more-an objective quite different from the one many are accustomed to in a traditional monolithic system environment.

The Improving Team works with the various system-of-systems entities to set up any necessary improvement infrastructures or adapt existing structures to align with the core paradigms, principles, and practices reflected in the SoS Framework element. An essential aspect of the team's work is identifying a System-of-Systems Practices Group of interested individuals who can be led toward an understanding of the system-of-systems practices and can assume ownership of the improvement activities.

Another critical part of the SoS Pilot element is to identify and implement a prototype or demonstration project for the highest priority recommendations and action plans. In that project, the team's goal is to demonstrate the use of selected system-of-systems practices in a pilot setting. Initially, the Improving Team members act as mentors for the project, which provides an excellent opportunity to involve the System-of-Systems Practices Group. The following section outlines how the ISIS team is using the SoS Pilot element with a large government system of systems.

\subsubsection{SoS Pilot in Use: Activities}

In work with a large system of systems, one of the initial steps taken by the Improving Team was to work with the global system-of-systems entity to identify and establish a System-ofSystems Practices Group. The initial members of this group came from several of the constituents of the system of systems. This set of constituents was involved in some of the most critical interoperability problems identified in the SoS Analyze element. A charter was developed by the group and accepted by the global and constituent entities of the system of systems. While in time additional improvement infrastructure may be advisable, this charter was deemed sufficient for a first iteration.

The System-of-Systems Practices Group took the recommendations from the SoS Analyze element, prioritized them, and decided to focus initially on understanding and managing influence relationships among constituents. The group's action plan called for a small 
demonstration project to experiment with a set of interoperability maps, placing an initial emphasis on the schedule relationships and dependencies among a subset of the system-ofsystems constituents.

The Improving Team worked with the System-of-Systems Practices Group to define the purpose and scope for the demonstration project. The stated purpose was to provide early warning for interoperability issues that otherwise might not have been identified until too late - that is, to identify solutions before potential problems became actual problems. Further, the group wanted to determine whether its approach could be applied on a broader basis. The demonstration project would be constrained to a limited number of constituents; yet, it was sufficiently rich to examine a number of cross-program relationships. The duration of the demonstration project was constrained to an 8- to 10-week period.

Activities during the demonstration project included refining an initial Context Interoperability Map (from the SoS Analyze element), creating Node-centric Interoperability Maps, and creating a corresponding set of Arc-centric Interoperability Maps. The Improving Team worked with the System-of-Systems Practices Group to understand and apply the interoperability maps and other applicable aspects of the SoS Framework element.

\subsubsection{SoS Pilot in Use: Results}

From the pilot, we learned that interoperability maps should be developed incrementally. These maps should be updated as more is known about context, the individual nodes, and relationships. In general, we suggest that organizations

- establish a few important but easily understood attributes (e.g., schedule)

- begin with broadest identification of direct and indirect influences of some critical decision, rather than direct effects of many decisions

- have some early successes and learning before adding detail and more cases

- start with simple tools such as word processors and spreadsheets (Investing in more sophisticated tools should be explored during SoS Guide, after more experience has been gained.)

With assistance from the Improving Team and using information from the demonstration project, the System-of-Systems Practices Group analyzed the interoperability maps for patterns that could be symptomatic of interoperability problems. Several potential problems were, in fact, identified. (The project results and recommendations had not been presented to the global system-of-systems entity and key constituents at the time of the publishing of this technical note.) 


\subsection{SoS Guide}

The SoS Guide element is a set of techniques geared to expanding the use of the practices demonstrated in the SoS Pilot element to the entire range of organizations involved in a system-of-systems. The primary objectives for the SoS Guide element are

- describing readiness for the cultural and organizational assumptions of the SoS Framework element

- characterizing the adoption risks

- forming and executing an institutionalization plan for the broader COI

- creating or expanding the change infrastructure across the broader community

- monitoring the effectiveness of adopted practices and recommending adjustments as necessary

The SoS Guide element leverages traditional improvement strategies, where applicable. However, work is needed to expand these strategies to have greater effectiveness in the large multiorganization environments of systems of systems. 


\section{Summary}

SoS Navigator is a set of integrated practices that address the challenges related to achieving effective interoperability in a large system-of-systems context. The constituents of such systems of systems are highly dynamic and involve diverse stakeholders. These systems of systems often evolve into existence and continue to evolve throughout their life cycles - as new constituents are built, existing systems connect to become constituents, and other constituents leave. Lines between development, acquisition, and operation cycles are increasingly blurred.

SoS Navigator helps organizations chart a technical, organizational, and operational path through this system-of-systems environment and prepare for the even more demanding environments of the future, Internet-scale systems of systems. SoS Navigator consists of a core set paradigms and principles, along with techniques to identify and improve the practices of organizations.

SoS Navigator was developed to provide concrete guidance to programs and organizations that are addressing the new realities of system-of-systems development and acquisition. SoS Navigator is based on real engagements with actual large-scale systems of systems. It has been used successfully to provide insights that had not been previously understood; those insights have been applied to avoid potentially expensive problems.

SoS Navigator is an evolving product. As organizations like FCS, USJFCOM, the medical community, and others gain expertise in building ever-larger systems of systems, the ISIS team intends to incorporate the improved and new practices they identify into SoS Navigator. Likewise, SoS Navigator will evolve as researchers identify new approaches in architecting, constructing, maintaining, and operating large-scale systems of systems.

The ISIS team welcomes your feedback on this discussion of the SoS Navigator technology and comments on your experiences with interoperability challenges. Contact the team at isissei@sei.cmu.edu. 


\section{References}

URLs are valid as of the publication date of this document.

[Carney 05] Carney, David; Fisher, David; \& Place, Pat. Topics in Interoperability: System-of-Systems Evolution (CMU/SEI-2005TN-002, ADA441303). Pittsburgh, PA: Software Engineering Institute, Carnegie Mellon University, 2005.

http://www.sei.cmu.edu/publications/documents/05.reports /05tn002.html.

[CSI 05] Commission on Systemic Interoperability. Ending the Document Game: Connecting and Transforming Your Healthcare Through Information Technology. http://endingthedocumentgame.gov/PDFs /entireReport.pdf (2005).

[Francis 04] Francis, Paul L. Defense Acquisitions: The Army's Future Combat Systems' Features, Risks, and Alternatives (Testimony before the Subcommittee on Tactical Air and Land Forces, Committee on Armed Services, House of Representatives). http://www.gao.gov/new.items/d04635t.pdf (April 1, 2004).

[GPO 00]

[HHS 05]

U.S. Government Printing Office. Joint Vision 2020. http://www.dtic.mil/jointvision/jv2020.doc (2000).

U.S. Department of Health and Human Services. HHS Awards Contracts to Develop Nationwide Health Information Network. http://www.hhs.gov/news/press/2005pres/20051110.html (2005).

[Morris 04] Morris, Edwin; Levine, Linda; Meyers, Craig; Place, Pat; \& Plakosh, Dan. Systems of Systems Interoperability (SOSI): Final Report. (CMU/SEI-2004-TR-004). Pittsburgh, PA: Software Engineering Institute, Carnegie Mellon University. 2004. http://www.sei.cmu.edu/publications/documents/04.reports /04tr004.html. 


\begin{tabular}{|c|c|c|c|c|c|c|}
\hline \multicolumn{5}{|c|}{ REPORT DOCUMENTATION PAGE } & \\
\hline \multicolumn{7}{|c|}{ 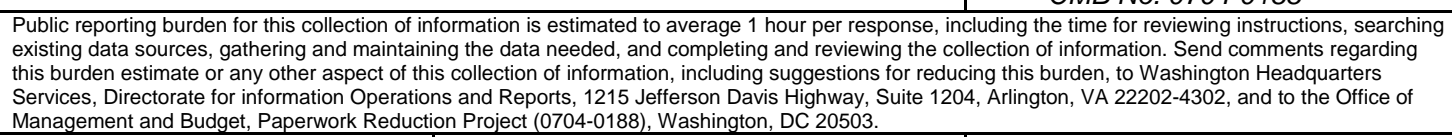 } \\
\hline \multicolumn{3}{|c|}{$\begin{array}{l}\text { 1. AGENCY USE ONLY } \\
\text { (Leave Blank) }\end{array}$} & \multicolumn{2}{|c|}{$\begin{array}{l}\text { 2. REPORT DATE } \\
\text { April } 2006\end{array}$} & \multicolumn{2}{|c|}{$\begin{array}{l}\text { 3. REPORT TYPE AND DATES COVERED } \\
\text { Final }\end{array}$} \\
\hline & \multicolumn{4}{|c|}{$\begin{array}{l}\text { System-of-Systems Navigator: An Approach for Managing System-of- } \\
\text { Systems Interoperability }\end{array}$} & \multicolumn{2}{|c|}{ FA8721-05-C-0003 } \\
\hline \multicolumn{7}{|c|}{$\begin{array}{ll}\text { 6. } & \text { AUTHOR(s) } \\
& \text { Lisa Brownsword, Da }\end{array}$} \\
\hline \multicolumn{5}{|c|}{$\begin{array}{l}\text { 7. PERFORMING ORGANIZATION NAME(S) AND ADDRESS(ES) } \\
\text { Software Engineering Institute } \\
\text { Carnegie Mellon University } \\
\text { Pittsburgh, PA } 15213\end{array}$} & \multicolumn{2}{|c|}{$\begin{array}{ll}8 . & \text { PERFORMING ORGANIZATION } \\
\text { REPORT NUMBER } \\
\text { CMU/SEI-2006-TN-019 }\end{array}$} \\
\hline & \multicolumn{4}{|c|}{$\begin{array}{l}\text { SPONSORING/MONITORING AGENCY NAME(S) AND ADDRESS(ES) } \\
\text { HQ ESC/XPK } \\
5 \text { Eglin Street } \\
\text { Hanscom AFB, MA 01731-2116 }\end{array}$} & \multicolumn{2}{|c|}{$\begin{array}{l}\text { 10. SPONSORING/MONITORING AGENCY } \\
\text { REPORT NUMBER }\end{array}$} \\
\hline \multicolumn{7}{|c|}{ 11. SUPPLEMENTARY NOTES } \\
\hline \multicolumn{5}{|c|}{$\begin{array}{l}\text { 12A DISTRIBUTION/AVALABBILITY STATEMENT } \\
\text { Unclassified/Unlimited, DTIC, NTIS }\end{array}$} & \multicolumn{2}{|c|}{ 12B DISTRIBUTION CODE } \\
\hline \multirow{2}{*}{\multicolumn{7}{|c|}{$\begin{array}{l}\text { We have crossed a threshold where most of our large software systems can no longer be constructed as } \\
\text { monoliths specified by a single, focused, and unified team; implemented as a unit; and tested to be within } \\
\text { known performance limits. They are now constructed as groups of interoperating systems (as systems of } \\
\text { systems) developed by different but sometimes related teams and made to interoperate through various } \\
\text { forms of interfaces. Unfortunately, while we can easily conceive these large systems of systems, we have } \\
\text { trouble building them. Software engineering practices have not kept pace, and the problem will only get worse } \\
\text { as the community begins to build Internet-scale systems of systems like the Global Information Grid. } \\
\text { This technical note introduces the System-of-Systems Navigator (SoS Navigator), the collection and } \\
\text { codification of essential practices for building large-scale systems of systems. These practices have been } \\
\text { identified through the work of the Integration of Software-Intensive Systems Initiative at the Carnegie Mellon } \\
\text { Software Engineering Institute. SoS Navigator provides tools and techniques to characterize organizational, } \\
\text { technical, and operational enablers and barriers to success in a system of systems; identify improvement } \\
\text { strategies; and pilot and institutionalize these strategies. }\end{array}$}} \\
\hline & & & & & & \\
\hline & $\begin{array}{l}\text { SUBJECT TERMS } \\
\text { Interoperability, syste } \\
\text { scale }\end{array}$ & & stems of systems, large & e, Internet- & \multicolumn{2}{|c|}{$\begin{array}{l}\text { 15. NUMBER OF PAGES } \\
38\end{array}$} \\
\hline \multicolumn{7}{|c|}{ 16. PRICE CODE } \\
\hline & $\begin{array}{l}\text { SECURITY CLASSIFICATION } \\
\text { OF REPORT } \\
\text { Unclassified }\end{array}$ & & $\begin{array}{l}\text { SECURITY CLASSIFICATION OF } \\
\text { THIS PAGE } \\
\text { Unclassified }\end{array}$ & $\begin{array}{l}\text { 19. SECURITY CLAS } \\
\text { ABSTRACT } \\
\text { Unclassifie }\end{array}$ & SIFICATION OF & $\begin{array}{l}\text { 20. LIMITATION OF ABSTRACT } \\
\text { UL }\end{array}$ \\
\hline
\end{tabular}

